\title{
Dissolved organic carbon lability and stable isotope shifts during microbial decomposition in a tropical river system
}

\author{
N. Geeraert ${ }^{1}$, F. O. Omengo ${ }^{1,2}$, G. Govers ${ }^{1}$, and S. Bouillon ${ }^{1}$ \\ ${ }^{1} \mathrm{KU}$ Leuven, Department of Earth and Environmental Sciences, Leuven, Belgium \\ ${ }^{2}$ Kenya Wildlife Service, Nairobi, Kenya \\ Correspondence to: N. Geeraert (naomi.geeraert@ees.kuleuven.be)
}

Received: 13 July 2015 - Published in Biogeosciences Discuss.: 11 August 2015

Revised: 4 January 2016 - Accepted: 14 January 2016 - Published: 26 January 2016

\begin{abstract}
A significant amount of carbon is transported to the ocean as dissolved organic carbon (DOC) in rivers. During transport, it can be transformed through microbial consumption and photochemical oxidation. In dark incubation experiments with water from the Tana River, Kenya, we examined the consumption of DOC through microbial decomposition and the associated change in its carbon stable isotope composition $\left(\delta^{13} \mathrm{C}\right)$. In 15 of the 18 incubations, DOC concentrations decreased significantly by 10 to $60 \%$, with most of the decomposition taking place within the first $24-48 \mathrm{~h}$. After 8 days, the remaining DOC was up to $3 \%$ o more depleted in ${ }^{13} \mathrm{C}$ compared with the initial pool, and the change in $\delta^{13} \mathrm{C}$ correlated strongly with the fraction of DOC remaining. We hypothesize that the shift in $\delta^{13} \mathrm{C}$ is consistent with greater microbial lability of DOC originating from herbaceous $\mathrm{C}_{4}$ vegetation than DOC derived from woody $\mathrm{C}_{3}$ vegetation in the semi-arid lower Tana. The results complement earlier findings that the stable isotope concentration of riverine DOC does not necessarily reflect the proportion of $\mathrm{C}_{3}$ and $\mathrm{C}_{4}$-derived DOC in the catchment: besides spatial distribution patterns of different vegetation types, processing within the river can further influence the $\delta^{13} \mathrm{C}$ of riverine OC.
\end{abstract}

\section{Introduction}

Rivers form the main connection between the terrigenous and oceanic organic carbon (OC) pools. Although rivers were previously seen as mere conduits of water and material, this is no longer the case (Cole et al., 2007; Battin et al., 2009; Aufdenkampe et al., 2011). Indeed, only $0.9 \mathrm{PgC}^{-1}$ of the global $\mathrm{C}$ input into inland waters, ranging between 1.9 and 2.7 $\mathrm{PgC} \mathrm{yr}^{-1}$, is delivered to the ocean (Cole et al., 2007; Battin et al., 2009; Regnier et al., 2013). Of the total OC flux, $73 \pm 21 \%$ is exported as dissolved carbon (AlvarezCobelas et al., 2012). Despite the significant amount of terrigenous carbon entering the river systems, relatively little organic material with a terrigenous signature can be found in the ocean (Raymond and Bauer, 2001; Bianchi and Bauer, 2011; Marìn-Spiotta et al., 2014). Therefore, it is important to have a better understanding of the changes $\mathrm{OC}$ is subjected to and at which point those changes occur during their transport towards the oceans. Two processes, photochemical oxidation and microbial consumption, are able either to mineralize the terrigenous $\mathrm{OC}$, or transform it in such a way that its characteristics resemble the oceanic OC (Bianchi and Bauer, 2011; Lalonde et al., 2014; Marìn-Spiotta et al., 2014). When this transformation of the OM characteristics occurs during transport in the rivers, it may lead to inconsistent characteristics between the terrestrial input, what is present in the river and the OM which is delivered to the ocean, if the transformation processes are not fully understood.

Photochemical processes can occur directly, when the chromophoric dissolved organic matter (DOM) becomes excited under the influence of UV and visible light, leading to transformation within the molecules, or indirectly when free radicals are formed which react with organic compounds (Amon and Benner, 1996; Lalonde et al., 2014). Compared with carbohydrates, lignin components are found to be much more susceptible to photochemical degradation, despite their resistance to biological degradation (Opsahl and Benner, 1998; Opsahl and Zepp, 2001; Spencer et al., 2009). A higher decomposition rate of lignin compared to the decomposition 


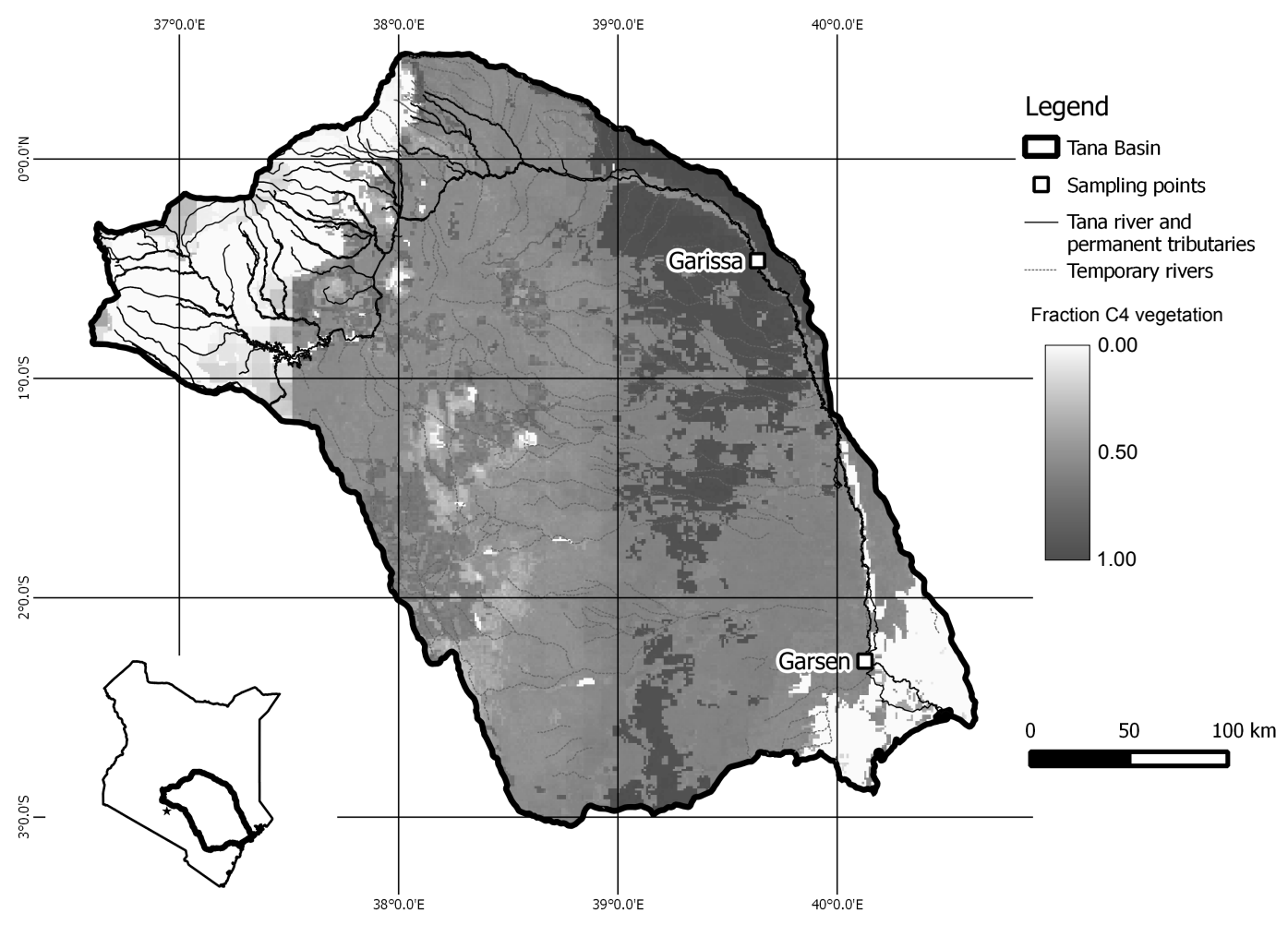

Figure 1. The Tana River with the indication of the two sampling locations in the lower catchment. The shading represents the fraction of $\mathrm{C}_{4}$ vegetation, based on the isoscapes of Still and Powell (2010). The inset indicates the Tana River basin within Kenya.

rate of the remaining constituents of the DOC pool would lead to a ${ }^{13} \mathrm{C}$ enrichment of the remaining DOC pool, as lignin is more depleted in ${ }^{13} \mathrm{C}$ than the bulk DOM (Opsahl and Zepp, 2001). An increase in the $\delta^{13} \mathrm{C}$ signature of DOC under the influence of UV light has indeed been observed in different river systems such as the Congo, Amazon, and Mississippi rivers (Opsahl and Zepp, 2001; Spencer et al., 2009; Lu et al., 2013; Lalonde et al., 2014).

The biodegradable fraction of DOC can be quantified by the loss of DOC by microbial consumption in dark incubation experiments (Servais et al., 1989). Several experiments have combined the effect of photochemical oxidation with microbial incubation, either by exposing filtered water to UV light followed by the addition of inoculum (Amon and Benner, 1996; Lalonde et al., 2014), or by allowing both processes to act simultaneously (Benner and Kaiser, 2011; $\mathrm{Lu}$ et al., 2013). These studies have consistently found that photochemical oxidation degraded a larger fraction of the DOC, compared to biological consumption (Amon and Benner, 1996; Benner and Kaiser, 2011; Lu et al., 2013; Lalonde et al., 2014). Furthermore, microbial and photochemical processes exert greater effect in combination than independently (Benner and Kaiser, 2011; Lu et al., 2013).

Photochemical processes only take place in the light penetrated upper layer of a river, while microbial consumption can take place in the entire water column. Besides micro- bial consumption in the water column, microbial activity in biofilms can also affect the DOC concentration through consumption, production or transformation of DOC (Battin et al., 2003; Romanì et al., 2004). The influence of the benthic system on the DOC dynamics depends strongly on the characteristics of the riverine system and will here not be discussed further. Depth-integrated estimates for the Amazon River, excluding the benthic system, indicate that microbial consumption is the dominant process affecting DOC degradation, accounting for a loss of ca. $0.75 \%$ of the DOC per day, while only $0.01 \%$ for photochemical oxidation (Amon and Benner, 1996).

Studies have not found a significant change in $\delta^{13} \mathrm{C}$ associated with microbial consumption of DOC, with the exception of the Congo and Parana rivers, which experienced a decrease in $\delta^{13} \mathrm{C}$ by 1.2 and $2.5 \%$ (Lalonde et al., 2014). According to Lalonde et al. (2014), the different behavior for these rivers might be due to the importance of the $\mathrm{C}_{4}$ carbon fixation pathway in their catchments.

In the discussion about processes affecting the stable carbon isotope signature of DOC, it is important to distinguish between isotope fractionation and selective decomposition. In processes subjected to isotope fractionation, there is a preferential use of the light or heavy isotopes of a homogeneous substrate because it is energetically more favorable. When the original substrate is not homogeneous, the isotope 
signature of the different components might be different. If one of those components decomposes at a faster rate than others (i.e. selective decomposition takes place), the isotope signature of the remaining substrate will shift towards the isotope signature of the less degradable component. During the degradation of DOC in aquatic systems, selective decomposition might be the main reason for changes in isotope signatures; Opsahl and Zepp (2001) have demonstrated that the isotope shift during photochemical oxidation is caused by the preferential decomposition of lignin components, which are isotopically lighter than the remaining ${ }^{13} \mathrm{C}$-enriched carbohydrates.

We measured DOC concentration and the corresponding $\delta^{13} \mathrm{C}_{\mathrm{DOC}}$ signatures at high temporal resolution at two stations ca. $385 \mathrm{~km}$ apart on the lower Tana River, Kenya during three different campaigns in 2012, 2013 and 2014. During the first campaign (2012), we observed a significant downstream decrease in DOC concentration (from 3.30 to $2.36 \mathrm{mg} \mathrm{L}^{-1}$ ). At the same time, we noticed a decrease in $\delta^{13} \mathrm{C}_{\mathrm{DOC}}$ (from -22.6 to $-24.6 \%$ o). These findings suggested that significant DOC processing took place in the lower Tana River. However, quantifying decomposition rates required more detailed information than can be obtained from river time series alone. Therefore, we performed dark incubation experiments during the two last campaigns (2013 and 2014) in order to assess the stability of DOC over the travel time of the water between both stations (ca. 5 days). We focused on the microbial decomposition of DOC, as light penetration was limited due to the high sediment load of the river, typically $>100 \mathrm{mg} \mathrm{L}^{-1}$ in the lower Tana (Bouillon et al., 2009; Tamooh et al., 2012, 2014). We also tested whether decomposition dynamics were significantly affected by the presence of POC and suspended sediment. The presence of POC could affect microbial degradation kinetics and DOC mineralization as it may function as a source of DOC.

\section{Material and methods}

The Tana River catchment $\left(95500 \mathrm{~km}^{2}\right)$ is characterized by a strong variation in climate: high rainfall (up to $3000 \mathrm{~mm} \mathrm{yr}^{-1}$ ) and relatively low temperatures (around $10^{\circ} \mathrm{C}$ ) occur in the highlands of the source area of the Tana (northwestern part of the basin, Fig. 1), while the area around Garissa is very warm (around $35^{\circ} \mathrm{C}$ ) and receives an annual amount of ca. $350 \mathrm{~mm} \mathrm{yr}^{-1}$, with high interannual variability (eastern part of the basin). The rainfall follows a bimodal distribution resulting in high discharge from April to June and from November to January.

The variability in climate results in strong variations in vegetation composition, which likely influences the isotope composition of the riverine organic C (Fig. 1). The overall coverage of the catchment with $\mathrm{C}_{4}$ vegetation is $59 \%$, based on the isoscape map, which was improved by taking into account the Global Land Cover 2000 map and estimates of crop \% (Still and Powell, 2010). The isoscape map, presenting the spatial distribution of vegetation stable carbon isotopes, was converted to represent the ratio of $\mathrm{C}_{4}$ vegetation cover based on a 2-source mixing scenario with as end members $C_{3}$ vegetation and $C_{4}$ vegetation with a $\delta^{13} \mathrm{C}$ of -27 and $-12 \%$ respectively (i.e. the fractionation factors used for the construction of the isoscape maps; Still and Powell, 2010). Between the sampling sites, the river is fringed with tropical forest (whereby the total floodplain is seldom wider than $5 \mathrm{~km}$ ), while savannah and open shrubs dominate outside of the floodplain.

Water samples were taken from the lower Tana River at Garissa and near Garsen (Fig. 1). The distance along the river between the sampling points is $385 \mathrm{~km}$, and the stretch has only ephemeral tributaries, which hold water only a few days per year. In the wet season of 2013 (May-June), the samples were taken during the decreasing limb of a large seasonal discharge pulse, resulting in extensive flooding between the two sampling sites. During the wet season of 2014 (AprilMay), the samples covered the full wet season which was characterized by two minor discharge peaks without significant flooding. The samples were regularly spaced throughout the campaigns as a new incubation series was started once the previous one was finished.

Grab water samples were taken from the middle of two bridges crossing the river. One $40 \mathrm{~mL}$ subsample was used to determine the initial DOC concentration. This water was vacuum filtered on a pre-combusted $\mathrm{GF} / \mathrm{F}$ filter (pore size: $0.7 \mu \mathrm{m}$ ) and subsequently filtered with a $0.2 \mu \mathrm{m}$ Sartorius Minisart syringe filter. The filtration was started as soon as possible after sampling, but due to the high sediment load in the water, it could take up to $2 \mathrm{~h}$ before the filtration was finished. Finally, $50 \mu \mathrm{L}$ of $\mathrm{H}_{3} \mathrm{PO}_{4}$ was added for preservation. These samples were stored in the dark and upon return from the field in the fridge, until analysis, which was within 4 months of sampling.

The remainder of the grab water sample was used to monitor DOC degradation. In 2013, the degradation rate of DOC was measured under two different treatments: with and without removal of particulate organic carbon (POC). In the first treatment, $500 \mathrm{~mL}$ of unfiltered water was stored in a glass bottle wrapped in $\mathrm{Al}$ foil. In the second, $500 \mathrm{~mL}$ of river water was first filtered to $0.2 \mu \mathrm{m}$ as described above for DOC sampling. After filtration, $5 \mathrm{~mL}$ of unfiltered river water was added to serve as inoculum. Similar to the unfiltered set-up, the water was then kept in foil-covered glassware. To avoid large changes in temperature, both bottles were submerged either directly in the river water, or in a coolbox with water as an isolator from outside temperature changes. The water in the bottles was not stirred during the incubation. Water temperature was regularly measured and ranged between 25 and $30^{\circ} \mathrm{C}$. At days 2, 4, 6, 8 and 10, a subsample of ca. $40 \mathrm{~mL}$ was extracted from the incubation bottle, filtered with a syringe filter (Sartorius Minisart, pore size: $0.2 \mu \mathrm{m}$ ) and preserved with $50 \mu \mathrm{L}$ of $\mathrm{H}_{3} \mathrm{PO}_{4}$ in glass vials with Teflon-coated 
Table 1. Concentration and isotopic signatures at the start (day 0) and the end (day 8) of the incubation series (the full data set including all intermediate measurements, can be found in the Supplement).

\begin{tabular}{|c|c|c|c|c|c|c|c|c|c|c|c|}
\hline Site $^{\mathrm{a}}$ & $\mathrm{yr}$ & Date $^{b}$ & Filt. $^{\mathrm{c}}$ & $\begin{array}{c}\text { Initial C } \\
\left(\mathrm{mgL}^{-1}\right)\end{array}$ & $\begin{array}{r}\text { Final C } \\
\left(\mathrm{mg} \mathrm{L}^{-1}\right)\end{array}$ & $\%$ Rem. $^{\mathrm{d}}$ & $\begin{array}{r}\text { Initial } \delta^{13} \mathrm{C} \\
(\% \circ)\end{array}$ & $\begin{array}{r}\text { Final } \delta^{13} \mathrm{C} \\
(\% o)\end{array}$ & $\begin{array}{l}\Delta \delta^{\mathrm{e}} \\
(\% o)\end{array}$ & $\begin{array}{r}\text { Init. } \mathrm{MR}^{\mathrm{f}} \\
\left(\mathrm{mgL}^{-1} \text { day }^{-1}\right)\end{array}$ & $\begin{array}{r}\text { Final MRg } \\
\left(\mathrm{mgL}^{-1} \mathrm{day}^{-1}\right)\end{array}$ \\
\hline GSA & 2013 & $04 / 05$ & $\mathrm{U}$ & 2.60 & 1.48 & 57 & -22.8 & -25.0 & -2.2 & 0.46 & 0.14 \\
\hline GSA & 2013 & $15 / 05$ & $\mathrm{U}$ & 1.54 & 1.48 & 96 & -24.3 & -24.5 & -0.2 & 0.05 & 0.01 \\
\hline GSA & 2013 & $26 / 05$ & $\mathrm{U}$ & 1.35 & & & -24.4 & & & -0.04 & \\
\hline GSA & 2013 & 05/06 & $\mathrm{U}$ & 1.41 & 1.39 & 99 & -23.9 & -23.3 & 0.6 & 0.06 & 0.00 \\
\hline GSA & 2013 & $04 / 05$ & $\mathrm{~F}$ & 2.60 & 2.07 & 80 & -22.8 & -23.3 & -0.5 & 0.28 & 0.07 \\
\hline GSA & 2013 & $15 / 05$ & $\mathrm{~F}$ & 1.54 & 1.43 & 93 & -24.3 & -24.0 & 0.3 & 0.03 & 0.01 \\
\hline GSA & 2013 & $26 / 05$ & $\mathrm{~F}$ & 1.35 & 1.28 & 95 & -24.4 & -24.2 & 0.1 & -0.02 & 0.01 \\
\hline GSA & 2013 & $05 / 06$ & $\mathrm{~F}$ & 1.41 & 1.34 & 95 & -23.9 & -23.6 & 0.3 & -0.02 & 0.01 \\
\hline GSN & 2013 & $03 / 05$ & $\mathrm{U}$ & 5.43 & 3.68 & 68 & -25.0 & -25.3 & -0.3 & 0.68 & 0.22 \\
\hline GSN & 2013 & $14 / 05$ & $\mathrm{U}$ & 4.09 & 2.43 & 59 & -23.5 & -24.7 & -1.3 & 0.70 & 0.21 \\
\hline GSN & 2013 & $26 / 05$ & $\mathrm{U}$ & 4.00 & 1.80 & 45 & -21.9 & -24.8 & -2.9 & 0.94 & 0.27 \\
\hline GSN & 2013 & $06 / 06$ & $\mathrm{U}$ & 3.26 & 1.58 & 49 & -21.6 & -24.4 & -2.7 & 0.77 & 0.21 \\
\hline GSN & 2013 & $03 / 05$ & $\mathrm{~F}$ & 5.43 & 4.20 & 77 & -25.0 & -24.7 & 0.3 & 0.58 & 0.15 \\
\hline GSN & 2013 & $14 / 05$ & $\mathrm{~F}$ & 4.09 & 2.69 & 66 & -23.5 & -24.4 & -0.9 & 0.63 & 0.18 \\
\hline GSN & 2013 & $26 / 05$ & $\mathrm{~F}$ & 4.00 & 1.93 & 48 & -21.9 & -24.3 & -2.4 & 0.93 & 0.26 \\
\hline GSN & 2013 & $06 / 06$ & $\mathrm{~F}$ & 3.26 & 1.66 & 51 & -21.6 & -23.6 & -2.0 & 0.77 & 0.20 \\
\hline GSA & 2014 & $02 / 04$ & $\mathrm{~F}$ & 4.99 & & & -23.5 & & & 1.51 & \\
\hline GSA & 2014 & $11 / 04$ & $\mathrm{~F}$ & 2.99 & 2.23 & 74 & -23.0 & -24.7 & -1.7 & 0.35 & 0.10 \\
\hline GSA & 2014 & $20 / 04$ & $\mathrm{~F}$ & 4.57 & 2.01 & 44 & -22.4 & -24.3 & -1.9 & 2.29 & 0.32 \\
\hline GSA & 2014 & $29 / 04$ & $\mathrm{~F}$ & 2.25 & 1.46 & 65 & -22.1 & -23.7 & -1.5 & 0.39 & 0.10 \\
\hline GSA & 2014 & $08 / 05$ & $\mathrm{~F}$ & 1.59 & 1.34 & 85 & -23.1 & -23.5 & -0.4 & 0.09 & 0.03 \\
\hline GSN & 2014 & $06 / 04$ & $\mathrm{~F}$ & 3.91 & 1.81 & 46 & -23.9 & -24.1 & -0.3 & 0.97 & 0.26 \\
\hline GSN & 2014 & $15 / 04$ & $\mathrm{~F}$ & 2.11 & 1.87 & 89 & -24.3 & -24.8 & -0.5 & 0.10 & 0.03 \\
\hline GSN & 2014 & 24/04 & $\mathrm{F}$ & 2.98 & 2.44 & 82 & -24.0 & -24.0 & 0.0 & 0.25 & 0.07 \\
\hline GSN & 2014 & $03 / 05$ & $\mathrm{~F}$ & 2.40 & 1.91 & 80 & -23.4 & -23.4 & 0.0 & 0.21 & 0.06 \\
\hline GSN & 2014 & $12 / 05$ & $\mathrm{~F}$ & 2.34 & 1.56 & 67 & -22.3 & -24.0 & -1.7 & 0.25 & 0.10 \\
\hline
\end{tabular}

${ }^{\mathrm{a}}$ GSA, Garissa and GSN, Garsen. ${ }^{\mathrm{b}}$ Date of day 0 of the incubation series. ${ }^{\mathrm{c}} \mathrm{U}$, unfiltered for incubation; F, filtered with addition of inoculum. ${ }^{\mathrm{d}}$ Proportion of initial DOC concentration remaining at the end of the incubation. ${ }^{\mathrm{e}}$ Change in $\delta^{13} \mathrm{C}$ between start and end of the incubation. ${ }^{\mathrm{f}}$ Mineralization rate from day 0 to day $2 .{ }^{\mathrm{g}}$ Mineralization rate from day 0 to day 8.

screw caps. We carried out four series of incubation experiments (both filtered and unfiltered) at each location.

In 2014, five incubation series were carried out at each location, but only with filtered water (second treatment). The methodology was identical to the one used in 2013, except that subsamples were taken at days 1,2,3,5 and 8 in order to provide a higher time resolution during the early stages of the incubations.

DOC concentration and isotopic signature were measured with a wet oxidation (heated persulfate) TOC analyzer (IO Analytical Aurora 1030W), coupled via a custom-made cryofocussing device with an isotope ratio mass spectrometer (ThermoFinnigan DeltaV Advantage; St-Jean, 2003). Calibrations were based on a 2-point calibration (IAEA-C6: $\delta^{13} \mathrm{C}$ $-10.4 \%$ and an internal standard, sucrose: $\delta^{13} \mathrm{C}-26.99 \%$ ). Based on replicates of the standards, the error in the concentration measurements was $<3 \%$ and the standard deviation for the $\delta^{13} \mathrm{C}$ measurements was $<0.2 \%$.

Decay rates, i.e. absolute rates of DOC loss per unit of time, over the whole incubation period were calculated based on the concentration difference between the day of in situ sampling (day 0) and day 8, which is the last common day between the measurements in 2013 and 2014. Initial decay rates were calculated over the first 2 days.
We calculated the concentration $\left(C_{\min }\right)$ and $\delta^{13} \mathrm{C}$ signature $\left(\delta^{13} C_{\min }\right)$ of the DOC fraction lost to mineralization during the incubation period based on a 2 -source mixing scenario:

$C_{\text {min }}=C_{\text {init }}-C_{\text {fin }}$

$\delta^{13} C_{\text {min }}=\frac{C_{\text {init }} \cdot \delta^{13} C_{\text {init }}-C_{\text {fin }} \cdot \delta^{13} C_{\text {fin }}}{C_{\text {init }}-C_{\text {fin }}}$

The initial concentration $\left(C_{\text {init }}\right)$ and $\delta^{13} C$ signature $\left(\delta^{13} C_{\text {init }}\right)$ were those measured on day 0 , while the final concentration $\left(C_{\text {fin }}\right)$ and $\delta^{13} \mathrm{C}$ signature $\left(\delta^{13} C_{\text {fin }}\right)$ were those measured on day 8 . Seven series were excluded in this analysis because the total mineralization rates were so low $\left(\leq 0.01 \mathrm{mg} \mathrm{L}^{-1} \mathrm{day}^{-1}\right.$, Table 1) that no realistic isotope signatures for the mineralized fraction were obtained. For the series that were retained $(n=19)$, the standard error on the isotopic signature of the mineralized DOC was on average $4.3 \pm 1.7 \%$, based on standard error propagation methods of the uncertainty on the measurements.

Statistical tests were performed in R. The non-parametric paired Wilcoxon signed rank test was applied to test for differences in concentration or isotope values at different times throughout the incubation series. Average values are given \pm the standard deviation. The robust linear regression was done by using an M-estimator (R-package: MASS). 


\section{Results and discussion}

\subsection{Comparison of incubation experiments with and without POC}

In order to assess the influence of the POC on the mineralization process, we will first compare the two different treatments of the eight incubation series of 2013. In the incubation series with less than $10 \%$ decomposition of the initial DOC $(n=3)$, the presence of POC resulted in ca. $3 \%$ less removal of DOC (Fig. 2a, Table 1). In the incubation series with more than $10 \%$ decrease in initial DOC $(n=5)$, the final concentration of DOC was systematically higher (ca. $10 \%$ ) in the incubation series without POC. A similar pattern was observed for $\delta^{13} \mathrm{C}_{\mathrm{DOC}}$ (Fig. 2b, Table 1), whereby the samples with POC were on average ca. $0.3 \%$ o more depleted in ${ }^{13} \mathrm{C}$ than the ones without POC. In contrast to our initial assumptions, these two findings indicate that there was, within the time resolution of our sampling (i.e. $48 \mathrm{~h}$ ), no substantial net addition of DOC originating from the POC pool, which would have resulted in higher DOC concentrations throughout the incubation experiment. Mineralization rates over the first 2 days were on average $0.06 \pm 0.06 \mathrm{mg} \mathrm{L}^{-1} \mathrm{day}^{-1}$ higher in experiments with POC compared to those without POC (Table 1), likely due to the higher biomass of the heterotrophic microbial community in the presence of suspended matter. Because of the covariations between changes in DOC and $\delta^{13} \mathrm{C}_{\mathrm{DOC}}$ during both treatments and the similar range in mineralization rates at our sampling resolution (Table 1), the unfiltered incubation series is treated as equivalent to the filtered ones for the remainder of the discussion.

\subsection{Change in DOC concentration during microbial degradation}

The general pattern in the concentration of DOC was a reduction within the first 24 to $48 \mathrm{~h}$ (Fig. 3a, Supplement Table S1). After this initial period, during which up to $60 \%$ of the DOC was lost, the concentration remained relatively stable. Initial concentrations over the whole data set ranged between 1.35 and $5.43 \mathrm{mg} \mathrm{L}^{-1}$, with an average of $2.98 \pm$ $1.31 \mathrm{mg} \mathrm{L}^{-1}$. By day 8 of the incubation, this range was reduced to $1.28-4.20 \mathrm{mg} \mathrm{L}^{-1}$, and an average concentration of $1.96 \pm 0.73 \mathrm{mg} \mathrm{L}^{-1}$. Out of all series, only six samples from the upstream station (Garissa) in 2013 (three filtered ones and the corresponding unfiltered ones) showed minor degradation of DOC (a change of $<10 \%$ of the initial concentration). This limited decrease in concentration can be related to the low initial concentration $\left(<2 \mathrm{mg} \mathrm{L}^{-1}\right)$, which is similar in magnitude as the recalcitrant DOC at the end of the incubation series with significant mineralization (Fig. 4, Table 1).

Paired Wilcoxon signed rank tests over all the filtered series, indicated that the concentration at day 2 was significantly different $(p<0.01)$ from the initial concentration,
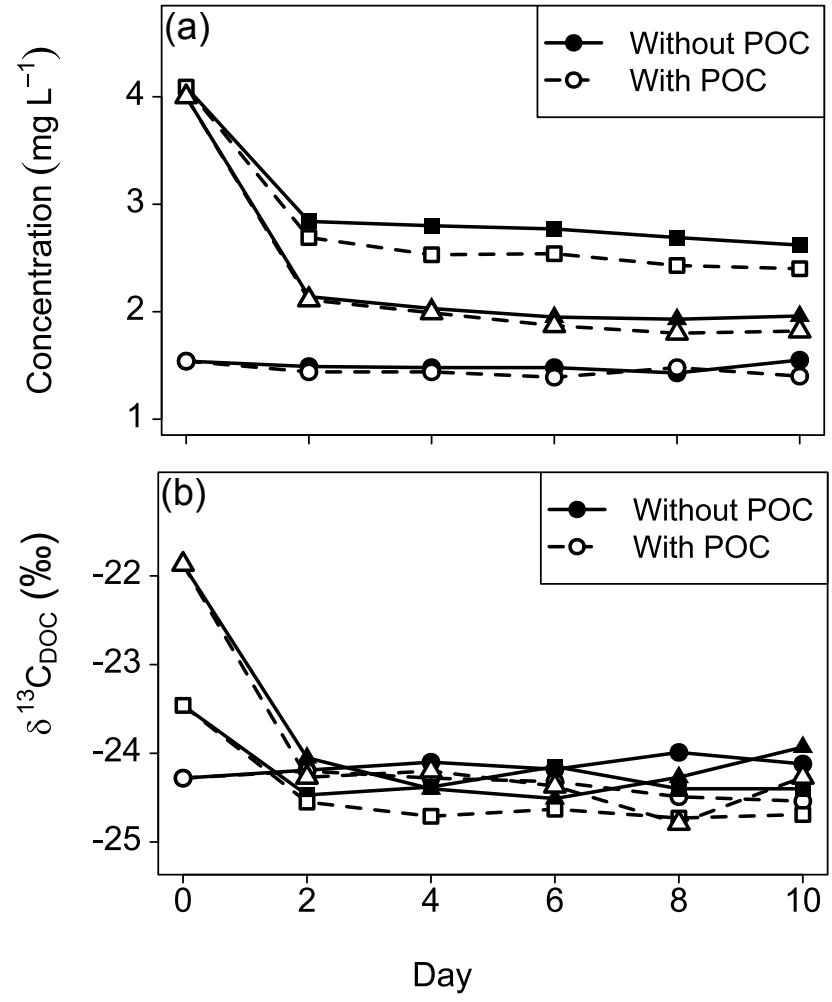

Figure 2. Comparison of evolution of (a) DOC concentration and (b) stable carbon isotope ratio of DOC $\left(\delta^{13} \mathrm{C}_{\mathrm{DOC}}\right)$ over time, for incubations with POC (unfiltered) and without POC (filtered). The three incubation series (Garissa 15 May 2013 (circles), Garsen 14 May 2013 (squares) and Garsen 26 May 2013; triangles) are representative of the eight data series, as they give an example of the low, medium and high response of the DOC. No consistent difference was found between the different sampling sites. The full data set for all incubations can be found in the Supplement.

with a mean difference of $0.91 \pm 0.78 \mathrm{mg} \mathrm{L}^{-1}$. The concentration difference between day 2 and day 8 over all the filtered series was also significant (paired Wilcoxon signed rank test, $p<0.01$ ), with an average decrease in concentration of $0.09 \pm 0.08 \mathrm{mg} \mathrm{L}^{-1}$. The rate of decay of DOC ranged between 0.01 and $0.32 \mathrm{mg} \mathrm{L}^{-1} \mathrm{day}^{-1}$ over the whole incubation (day 0 to day 8), with on average $0.13 \pm 0.10 \mathrm{mg} \mathrm{L}^{-1} \mathrm{day}^{-1}$, while the decay rate during the first two incubation days reached up to $2.29 \mathrm{mg} \mathrm{L}^{-1}$ day, with an average of $0.51 \pm$ $0.53 \mathrm{mg} \mathrm{L}^{-1} \mathrm{day}^{-1}$ (Table 1). This is in the same order as the observations from the dark control experiments during the incubation of Amazonian waters, which had initial DOC concentrations around $9.6 \mathrm{mg} \mathrm{L}^{-1}$ and mineralization rates of $0.12-0.16 \mathrm{mg} \mathrm{L}^{-1} \mathrm{day}^{-1}$ (Amon and Benner, 1996). However, they did not observe that the majority of the degradation took place within the first days. High initial degradation rates were found during the experiments of Moody et al. (2013). Although the water from a peat-covered catchment had much higher initial DOC concentration (ca. $50 \mathrm{mg} \mathrm{L}^{-1}$ ) compared 

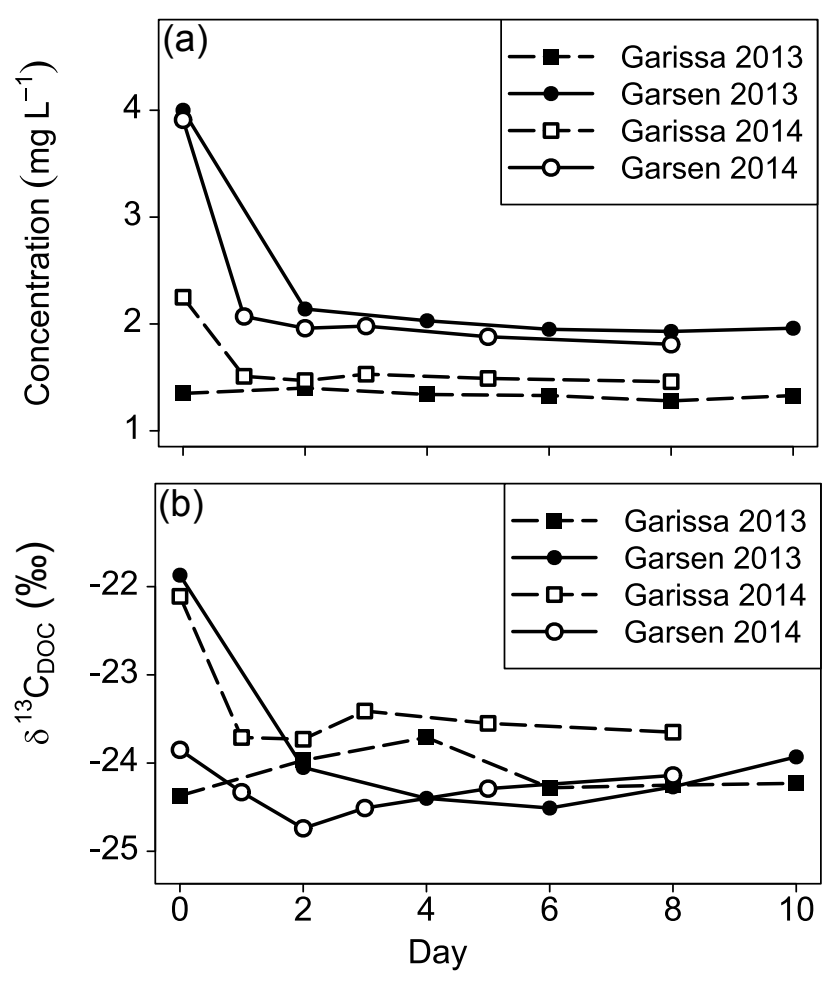

Figure 3. Evolution of (a) DOC concentration and (b) carbon stable isotope signature of DOC $\left(\delta^{13} \mathrm{C}_{\mathrm{DOC}}\right)$ during the 8- to 10-day incubations. Both panels show data from one incubation series per sampling site and per year (Garissa 26 May 2013, Garsen 26 May 2013, Garissa 29 April 2014, Garsen 6 April 2014), providing representative examples of the low, medium and high response of the DOC. No consistent difference was found between the different sampling sites or sampling years. The full data set and a similar figure with all the incubation series without POC can be found in the Supplement.

to our measurements, they similarly observed an average decline of $47 \%$ in DOC after 10 days dark incubation, with high degradation rates during the first two incubation days and a much lower rate thereafter.

\subsection{Changes in stable isotope signatures of DOC during microbial degradation}

Overall, $\delta^{13} \mathrm{C}_{\text {DOC }}$ signatures decreased consistently during microbial degradation (Fig. 3b, Table 1). However, there was considerable variation in magnitude of change between the different series. Some incubation series, mainly in 2013 at Garissa and in 2014 at Garsen, experienced hardly any change, while other series, especially in 2013 at Garsen, experienced a decrease up to $3.0 \%$. Initial $\delta^{13} \mathrm{C}$ values ranged between -25.0 and $-21.7 \%$ with an average value of $-23.3 \pm 1.0 \%$ for the whole data set, which is in line with previous measurements for the lower Tana River (Bouillon et al., 2009; Tamooh et al., 2012). Towards the end of the incubation (day 8 ), $\delta^{13} \mathrm{C}$ values had decreased significantly

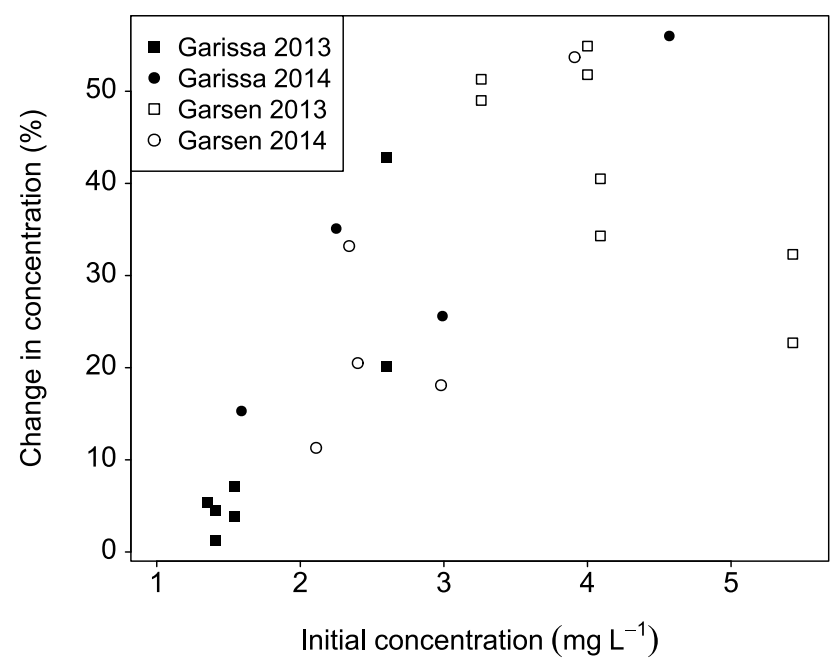

Figure 4. Relative change (in \%) between the initial concentration (day 0 ) and final concentration (day 8 ) in function of the initial concentration of the DOC. All available data are represented.

(paired Wilcoxon signed rank test, $p<0.05$ ), ranging between -25.3 and $-23.3 \%$ (avg. $-24.2 \pm 0.6 \%$ o).

The $\delta^{13} \mathrm{C}_{\mathrm{DOC}}$ values at day 2 were significantly different from initial $\delta{ }^{13} \mathrm{C}$ values (paired Wilcoxon signed rank test, $p<0.05$ ) over all the filtered incubation series, with a decrease of $0.8 \%$. In contrast to the concentration, no significant change in $\delta^{13} \mathrm{C}$ was detected between day 2 and day 8 (paired Wilcoxon signed rank test, $p>0.05$ ).

\subsection{Characterization of mineralized and remaining $\mathrm{C}$}

The change in $\delta^{13} \mathrm{C}$ was positively related to the proportion (\%) of DOC still present after incubation (Fig. 5). A large relative decrease in DOC led to a more ${ }^{13} \mathrm{C}$ depleted residue, implying that the mineralized fraction of the DOC was enriched in ${ }^{13} \mathrm{C}$ vs. the bulk initial DOC pool. Fitting a linear model by robust regression using an $\mathrm{M}$ estimator over the averaged points per incubation series over the whole data set resulted in $\Delta \delta=-3.87+0.041 \times(\% \mathrm{DOC}$ remaining $)$.

The isotopic signature of the mineralized DOC was significantly different (paired Wilcoxon signed rank test, $p<0.01$ ) from the initial DOC as well as from the remaining DOC (Fig. 6). The mineralized fraction of the DOC was more enriched in ${ }^{13} \mathrm{C}$ than the initial or remaining DOC, with average values of $-21.2 \pm 2.2,-23.1 \pm 1.1$ and $-24.3 \pm 0.6 \%$ o respectively. The concentration of the mineralized DOC was on average lower than that of the DOC which was more resistant to microbial degradation.

\subsection{Removal mechanism and origin of DOC}

Analogous to an isotopic shift due to selective photochemical oxidation of certain compounds (Opsahl and Zepp, 2001), the hypothesis can be formulated that selective decompo- 


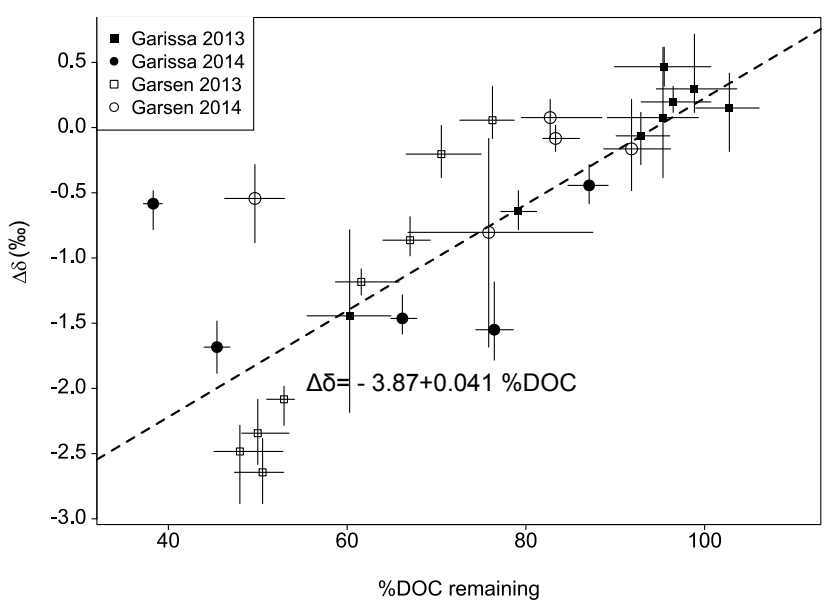

Figure 5. Change in isotopic signature between initial concentration (day 0 ) and later in the incubation series $(\Delta \delta)$ vs. the proportion $(\%)$ of DOC remaining after incubation. The points are average values over the five measurements per series and the lines indicate minimum and maximum values within that series. A robust linear regression model was applied for the regression line. Both filtered and unfiltered series are represented.

sition during microbial oxidation is the key mechanism to explain the shift in $\delta^{13} \mathrm{C}$ that we observed during DOC decomposition, whereby the isotopically heavier carbohydrates (Benner et al., 1987) were preferentially decomposed. However, if such a mechanism were to be generally valid, a similar shift would be expected in other types of aquatic systems (irrespective of the $\mathrm{C}_{3} / \mathrm{C}_{4}$ dominance in the catchment), yet previous studies have typically shown little or no change in $\delta^{13} \mathrm{C}$ during microbial degradation of DOC (Lu et al., 2013; Lalonde et al., 2014). However, a similar decrease in $\delta^{13} \mathrm{C}_{\mathrm{DOC}}$ due to microbial degradation has been shown for both the Congo and Parana rivers (Lalonde et al., 2014). One characteristic which both river systems have in common with the Tana River, is the presence of $\mathrm{C}_{4}$ vegetation within their catchment. A higher decomposition rate for the $\mathrm{C}_{4}$-derived DOC, as reported for soil organic carbon (Wynn and Bird, 2007), would indeed be consistent with the observed isotopic shift.

It is, however, not clear whether the different decomposition rates are inherently related to the different photosynthetic pathways used by $\mathrm{C}_{3}$ and $\mathrm{C}_{4}$ vegetation, or to the fact that in tropical regions such as the Tana River catchment, $\mathrm{C}_{3}$ vegetation consists of shrubs and trees, which are more resistant to degradation, while $\mathrm{C}_{4}$ vegetation consists of grass species, which are more easily degraded. The latter option would appear more likely, as a study directly comparing the decomposition of $\mathrm{C}_{3}$ and $\mathrm{C}_{4}$ grasses has shown a greater decomposition rate for $\mathrm{C}_{3}$ grasses (Ross et al., 2002). More dedicated studies using a similar experimental approach as used here, but with mixtures of DOC originating from both $\mathrm{C}_{3}$ and $\mathrm{C}_{4}$ grasses would be required to verify the latter hy-

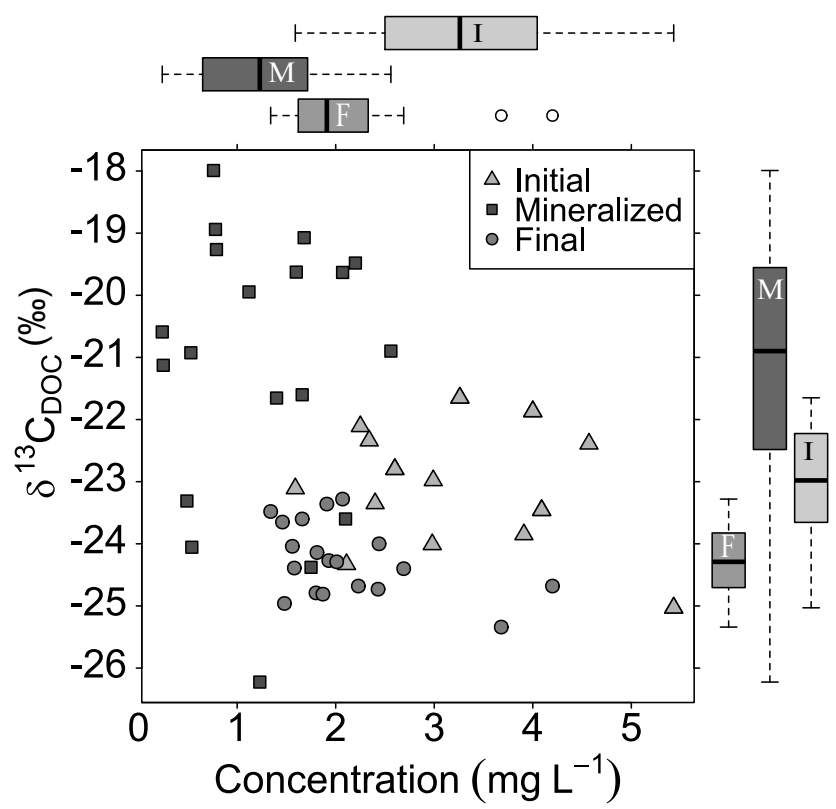

Figure 6. Calculated values of the concentration and isotopic signature of the mineralized DOC pool, for incubation series that experienced a sufficiently high loss of DOC. The horizontal box plots indicate the distribution of the concentration while the vertical ones indicate the distribution of the stable isotope signature for the initial (I), mineralized (M) and final (F) DOC. Incubation series with and without POC are represented, as long as the relative error on the concentration was less than $50 \%$.

pothesis. Besides the contrast between the vegetation types, a different age of the DOC from $\mathrm{C}_{3}$ and $\mathrm{C}_{4}$ vegetation can also be the reason for the preferential degradation of DOC with a $\mathrm{C}_{4}$ signature. Young DOC is preferentially utilized by bacteria (Raymond and Bauer, 2001). It can be hypothesized that the DOC delivered to the river consists of young DOC from the nearby floodplains with a dominance of $\mathrm{C}_{4}$ vegetation.

Microbial degradation was high during the initial phase (first $48 \mathrm{~h}$ ) in both sampling sites. Considering the water travel time ( $\sim 5$ days) between these sites, the high reactivity even at the downstream site implies that there is not merely a downstream transport of DOC which is progressively mineralized, but that a replenishment of the labile DOC pool must occur. Identifying the source of this DOC pool might assist in understanding the mineralization mechanisms. Possible DOC sources include (1) the POC suspended in the water which may release C into the DOC pool, (2) advection by the tributaries, (3) inputs from the floodplain during inundation, (4) photo-activation of a fraction of the DOC pool, (5) human activities, such as waste water inputs, (6) DOC release from river bed sediments, and (7) groundwater and subsurface water inputs through leaching of DOC from leaf litter. Only the first source was explicitly tested for in the experiments in 2013, and it appeared that after $48 \mathrm{~h}$, there was no net effect of the presence of POC. This does not com- 
pletely rule out POC as a source of DOC, as ambient conditions in a river setting are still different than in our experimental setup or because the temporal resolution of our samples was too coarse to capture the influence of the POC. The advection of DOC by tributaries is unlikely, as their water flow is very erratic, likely even absent in 2014, while the presence of labile DOC was fairly constant. Input from the flooded floodplain will have been important in Garsen during the flooding in 2013 as DOC concentrations were significantly higher. However, it can not explain the presence of labile DOC during the wet season of 2014 when no considerable flooding took place. Photochemical and microbial processes have indeed been found to enhance each other (Benner and Kaiser, 2011; Lu et al., 2013), and would need further examination in the Tana River, which has a limited light penetration depth due to a very high sediment load. Population density is very low along the area, and sewage inflow is unlikely to provide a fairly continuous DOC supply. The last two options, river bed sediments and groundwater and/or subsurface flow, are speculative, as no information on them is yet available. The analysis of optical characteristics of the dissolved organic matter pool (Jaffé et al., 2008; Lambert et al., 2015) could be a valuable complementary approach in order to understand the origin and processing of DOC in rivers.

\section{Conclusions}

Our experiments demonstrated that in the lower Tana River, a fraction of the DOC is highly susceptible to decomposition, similar to observations in other large river systems. While it was previously considered that bacterial mineralization of labile dissolved OM generally has little influence on $\delta^{13} \mathrm{C}_{\mathrm{DOC}}$ signatures, our results show that such a change should be taken into account, at least when considering environments with mixed $\mathrm{C}_{3} / \mathrm{C}_{4}$ inputs. A higher decomposition rate of the DOC with a higher ${ }^{13} \mathrm{C}$ signature will lead to an underestimation of the $\mathrm{C}_{4}$-derived carbon input in catchments if the residence time between the input of carbon and the sampling location allows significant microbial degradation.

In addition, the high reactivity of the DOC at both sites has raised the question about the origin of the labile DOC pool. The applied method was only able to exclude POC as a likely source of labile DOC in the experimental setup. Further research, including optical characterization, would be required to shed more light on the dynamical replacement of the labile DOC pool in river systems.

\section{The Supplement related to this article is available online at doi:10.5194/bg-13-517-2016-supplement.}

Acknowledgement. Funding was provided by the KU Leuven Special Research Fund, the Research Foundation Flanders (FWOVlaanderen, project G024012N), and an ERC Starting Grant (240002, AFRIVAL). We are grateful to the Kenya Wildlife Service (KWS) for assistance during field experiments and to Z. Kelemen for help with stable isotope analysis. We appreciated the constructive feedback of two anonymous reviewers and A. Nordström.

Edited by: G. Herndl

\section{References}

Alvarez-Cobelas, M., Angeler, D., Sánchez-Carillo, S., and Almendros, G.: A worldwide view of organic carbon export from catchments, Biogeochemistry, 107, 275-293, 2012.

Amon, R. and Benner, R.: Photochemical and microbial consumption of dissolved organic carbon and dissolved oxygen in the Amazon River system, Geochim. Cosmochim. Ac., 60, 17831792, 1996.

Aufdenkampe, A. K., Mayorga, E., Raymond, P. A., Melack, J. M., Doney, S. C., Alin, S. R., Aalto, R. E., and Yoo, K.: Riverine coupling of biogeochemical cycles between land, oceans, and atmosphere, Front. Ecol. Environ., 9, 53-60, 2011.

Battin, T. J., Kaplan, L. A., Newbold, J. D., and Hansen, C. M. E.: Contributions of microbial biofilms to ecosystem processes in stream mesocosms, Nature, 426, 439-442, 2003.

Battin, T. J., Luyssaert, S., Kaplan, L. A., Aufdenkampe, A. K., Richter, A., and Tranvik, L. J.: The boundless carbon cycle, Nat. Geosci., 2, 598-600, 2009.

Benner, R., Fogel, M. L., Sprague, E. K., and Hodson, R. E.: Depletion of ${ }^{13} \mathrm{C}$ in lignin and its implications for stable carbon isotope studies, Nature, 329, 708-710, 1987.

Benner, R. and Kaiser, K.: Biological and photochemical transformations of amino acids and lignin phenols in riverine dissolved organic matter, Biogeochemistry, 102, 209-222, 2011.

Bianchi, T. S. and Bauer, J. E.: Particulate organic carbon cycling and transformation, in: Treatise on Estuarine and Coastal Science, edited by: Wolansky, E. and McLusky, D., Academic Press, Waltham, 69-117, 2011.

Bouillon, S., Abril, G., Borges, A. V., Dehairs, F., Govers, G., Hughes, H. J., Merckx, R., Meysman, F. J. R., Nyunja, J., Osburn, C., and Middelburg, J. J.: Distribution, origin and cycling of carbon in the Tana River (Kenya): a dry season basin-scale survey from headwaters to the delta, Biogeosciences, 6, 2475-2493, doi:10.5194/bg-6-2475-2009, 2009.

Cole, J. J., Prairie, Y. T., Caraco, N. F., McDowell, W. H., Tranvik, L. J., Striegl, R. G., Duarte, C. M., Kortelainen, P., Downing, J. A., Middelburg, J. J., and Melack, J.: Plumbing the global carbon cycle: integrating inland waters into the terrestrial carbon budget, Ecosystems, 10, 172-185, 2007.

Jaffé, R., McKnight D. M., Maie, N. Cory, R., McDowell, W. H., and Campbell, J. L.: Spatial and temporal variations in DOM composition in ecosystems: the importance of long-term monitoring of optical properties, J. Geophys. Res., 113, G04032, doi:10.1029/2008JG000683, 2008.

Lalonde, K., Vähätalo, A. V., and Gélinas, Y.: Revisiting the disappearance of terrestrial dissolved organic matter in the ocean: a 
$\delta^{13} \mathrm{C}$ study, Biogeosciences, 11, 3707-3719, doi:10.5194/bg-113707-2014, 2014.

Lambert, T., Darchambeau, F., Bouillon, S., Alhou, B., Mbega, J., Teodoru, C. R., Nyoni, F. C., Massicotte, P., and Borges, A. V.: Landsacpe control on the spatial and temporal variability of chromophoric dissolved organic matter and dissolved organic carbon in large African rivers, Ecosystems, 18, 1-16, doi:10.1007/s10021-015-9894-5, 2015.

Lu, Y., Bauer, J. E., Canuel, E. A., Yamashita, Y., Chambers, R. M., and Jaffé, R.: Photochemical and microbial alteration of dissolved organic matter in temperate headwater streams associated with different land use, J. Geophys. Res.-Biogeo., 118, 566-580, 2013.

Marìn-Spiotta, E., Gruley, K. E., Crawford, J., Atkinson, E. E., Miesel, J. R., Greene, S., Cardona-Correa, C., and Spencer, R. G. M.: Paradigm shifts in soil organic matter research affect interpretations of aquatic carbon cycling: transcending disciplinary and ecosystem boundaries, Biogeochemistry, 117, 279-297, 2014.

Moody, C. S., Worrall, F., Evans, C. D., and Jones, T. G.: The rate of loss of dissolved organic carbon (DOC) through a catchment, J. Hydrol., 492, 139-150, 2013.

Opsahl, S. and Benner, R.: Photochemical reactivity of dissolved lignin in river and ocean waters, Limnol. Oceanogr., 43, 12971304, 1998.

Opsahl, S. P. and Zepp, R. G.: Photochemically-induced alteration of stable carbon isotope ratios $\left(\delta^{13} \mathrm{C}\right)$ in terrigenous dissolved organic carbon, Geophys. Res. Lett., 28, 2417-2420, 2001.

Raymond, P. A. and Bauer, J. E.: Use of ${ }^{14} \mathrm{C}$ and ${ }^{13} \mathrm{C}$ natural abundances for evaluating riverine, estuarine, and coastal DOC and POC sources and cycling: a review and synthesis, Org. Geochem. 32, 469-485, 2001.

Raymond, P. A. and Cole, J. J.: Gas exchange in rivers and estuaries: choosing a gas transfer velocity, Estuar. Coast., 24, 312-317, 2001.

Regnier, P., Friedlingstein, P., Ciais, P., Mackenzie, F. T., Gruber, N., Janssens, I. A., Laruelle, G. G., Lauerwald, R., Luyssaert, S., Andersson, A. J., Arndt, S., Arnosti, C., Borges, A. V., Dale, A. W., Gallego-Sala, A., Goddéris, Y., Goossens, N., Hartmann, J., Heinze, C., Ilyina, T., Joos, F., LaRowe, D. E., Leifeld, J., Meysman, F. J. R., Munhoven, G., Raymond, P. A., Spahni, R., Suntharalingam, P., and Thullner, M.: Anthropogenic perturbation of the carbon fluxes from land to ocean, Nat. Geosci., 6, 597-607, 2013.
Romanì, A. M., Guash, H., Muñoz, I., Ruana, J., Vilalta, E., Schwartz, T., Emtiazi, F., and Sabater, S.: Biofilm structure and function and possible implications for riverine DOC dynamics, Microb. Ecol., 47, 316-328, 2004.

Ross, D., Tate, K., Newton, P., and Clark, H.: Decomposability of $\mathrm{C}_{3}$ and $\mathrm{C}_{4}$ grass litter sampled under different concentrations of atmospheric carbon dioxide at a natural $\mathrm{CO}_{2}$ spring, Plant Soil, 240, 275-286, 2002.

Servais, P., Anzil, A., and Ventresque, C.: Simple method for determination of biodegradable dissolved organic carbon in water, Appl. Environ. Microb., 55, 2732-2734, 1989.

Spencer, R. G. M., Stubbins, A., Hernes, P. J., Baker, A., Mopper, K., Aufdenkampe, A. K., Dyda, R. Y., Mwamba, V. L., Mangangu, A. M., Wabakanghanzi, J. N., and Six, J.: Photochemical degradation of dissolved organic matter and dissolved lignin phenols from the Congo River, J. Geophys. Res., 114, G03010, doi:10.1029/2009JG000968, 2009.

Still, C. J. and Powell, R. L.: Continental-scale distributions of vegetation stable carbon isotope ratios, in: Isoscapes: Understanding Movement, Pattern, and Process on Earth through Isotope Mapping, Springer, Dordrecht, Heidelberg, London, New York, 179193, 2010.

St-Jean, G: Automated quantitative and isotopic $\left({ }^{13} \mathrm{C}\right)$ analysis of dissolved inorganic carbon and dissolved organic carbon in continuous-flow using a total organic carbon analyser, Rapid. Commun. Mass Spectrom., 17, 419-428, 2003.

Tamooh, F., Van den Meersche, K., Meysman, F., Marwick, T. R., Borges, A. V., Merckx, R., Dehairs, F., Schmidt, S., Nyunja, J., and Bouillon, S.: Distribution and origin of suspended matter and organic carbon pools in the Tana River Basin, Kenya, Biogeosciences, 9, 2905-2920, doi:10.5194/bg-9-2905-2012, 2012.

Tamooh, F., Meysman, F. J. R., Borges, A. V., Marwick, T. R., Van den Meersche, K., Dehairs, F., Merckx, R., and Bouillon, S.: Sediment and carbon fluxes along a longitudinal gradient in the lower Tana River (Kenya), J. Geophys. Res.-Biogeo., 119, 1340-1353, 2014.

Wynn, J. G. and Bird, M. I.: $\mathrm{C}_{4}$-derived soil organic carbon decomposes faster than its $\mathrm{C}_{3}$ counterpart in mixed $\mathrm{C}_{3} / \mathrm{C}_{4}$ soils, Glob. Change Biol., 13, 2206-2217, 2007. 